\title{
Association of basal serum testosterone levels with ovarian response and in vitro fertilization outcome
}

Yingying Qin ${ }^{1,2+}$, Zhiyi Zhao ${ }^{1,2+}$, Mei Sun ${ }^{1,2}$, Ling Geng ${ }^{1,2}$, Li Che ${ }^{3}$, Zi-Jiang Chen ${ }^{1,2^{*}}$

\begin{abstract}
Background: To evaluate basal testosterone (T) levels during follicular phase of the menstrual cycle as a predictor for ovarian response and in vitro fertilization (IVF) outcome.

Method: We analyzed data retrospectively from hospital-based IVF center including one thousand two hundred and sixty Chinese Han women under their first IVF cycle reached the ovum pick-up stage, without polycystic ovary syndrome (PCOS) or endometriosis undergoing long IVF protocol. Patients were divided into 2 groups. Group 1: patients with diminished ovarian reserve (basal FSH $>10 \mathrm{IU} / \mathrm{L})(\mathrm{n}=187)$; Group 2: patients with normal ovarian reserve (basal FSH $<=10 \mathrm{IU} / \mathrm{L})(\mathrm{n}=1073)$. We studied the association of basal $\mathrm{T}$ levels with ovarian response and IVF outcome in the two groups. Long luteal down-regulation protocol was used in all patients, that is, the gonadotropin releasing hormone agonist was administered in the midluteal phase of the previous cycle and use of recombinant FSH was started when satisfactory pituitary desensitization was achieved.

Results: Basal T levels were markly different between pregnant and non-pregnant women in Group 1; whereas not in Group 2. A testosterone level of $47.85 \mathrm{ng} / \mathrm{dl}$ was shown to predict pregnancy outcome with a sensitivity of $52.8 \%$ and specificity of $65.3 \%$; and the basal T was correlated with the numbers of large follicles (>14 mm) on HCG day in Group 1. Significantly negative correlations were observed between basal T, days of stimulation and total dose of gonadotropins after adjusting for confounding factors in both groups.

Conclusion: In women with diminished ovarian reserve, basal T level was a predictor for the number of large follicles on HCG day and pregnancy outcome; but could not in those with normal serum FSH. Basal T levels were associated with both days of stimulation and total dose of gonadotropins, indicating that lower level of T might relate with potential ovarian poor response.
\end{abstract}

\section{Background}

Ovarian response, the recruitment and development of multiple follicles followed by gonadotropins, is a key factor for in vitro fertilization (IVF) treatment cycle. The prediction of ovarian response before undertaking the expensive IVF treatment is important. However, the predictive value of various widely used markers, such as age, antral follicle count (AFC), levels of serum inhibin $\mathrm{B}$, serum anti-Müllerian hormone (AMH), basal serum follicle stimulating hormone (FSH) and estradiol $\left(\mathrm{E}_{2}\right)$, basal FSH/LH (luteinizing hormone) ratio, still appeared inconsistent and not accurate enough. A large amount

\footnotetext{
* Correspondence: chenzijiang@hotmail.com

+ Contributed equally

${ }^{1}$ Center for Reproductive Medicine, Shandong Provincial Hospital, Shandong University, Jinan, 250021, PR China

Full list of author information is available at the end of the article
}

of patients may respond poorly to gonadotropins in spite of normal screening parameters [1]. Therefore, it continues to be a challenge for reproductive physicians to identify poor ovarian reserve and the probability of pregnancy beforehand.

Androgens, primarily testosterone (T) and androstenedione, are noteworthy to enhance follicular recruitment [2], promote follicular growth and development [3,4], and increase insulin like growth factor 1 (IGF-1) expression in the primate ovary which plays an essential role in regulating follicular development $[3,5]$. Recent clinical reports with encouraging results demonstrated that cotreatment with androgen, such as dehydroepiandrosterone (DHEA) and Androderm (transdermal testosterone), could increase both quantity and quality of oocytes and embryos, and improve pregnancy outcomes in women with diminished ovarian function or even premature

\section{Ciomed Central}


ovarian failure [6-9]. Improved controlled ovarian hyperstimulation $(\mathrm{COH})$ and pregnancy outcomes by supplementation with aromatase inhibitors may be the consequence of increased intraovarian androgen, followed by the induction of FSH receptors on granulosa cell $[10,11]$. Nevertheless, controversy exists as to whether these protocols improve cycle outcome $[12,13]$.

Prompted by these findings, we hypothesized whether serum testosterone levels could predict ovarian response and IVF outcome. To the best of our knowledge, only a few studies have concerned this question with conflicting results. This might be explained by limited sample size and heterogeneous population mixed by patients with polycystic ovary syndrome (PCOS) and/or endometriosis as PCOS and endometriosis are associated with higher or lower serum T levels $[14,15]$. No published study focus on the role of basal $\mathrm{T}$ levels during stimulation cycle on the ovarian response and reproductive outcomes in women with either diminished or normal ovarian reserve. Thus, conclusive and definite data about the associations of basal serum $\mathrm{T}$ levels with ovarian response and IVF outcome are still lacking. The purpose of the present study is to evaluate the predictive value of basal $\mathrm{T}$ levels in women with both diminished and normal ovarian reserve on ovarian response and IVF outcome in a large $(n=1260)$ and homogeneous population undergoing IVF-ET.

\section{Methods}

\section{Study population}

One thousand two hundred and sixty Chinese Han patients under their first IVF-ET cycle reached the ovum pick-up stage undergoing IVF in the Center for Reproductive Medicine, Shandong Provincial Hospital, Shandong University from October, 2008 to January, 2010 were recruited. And we selected women who used only long protocol to avoid possible bias from different protocols. Exclusion criteria were women with either PCOS or endometriosis. Patients were divided into 2 groups. Group 1 included patients with diminished ovarian reserve $(\mathrm{n}=187)$ and Group 2 with normal ovarian reserve $(n=1073)$. Diminished ovarian reserve was defined as basal FSH value $>10 \mathrm{IU} / \mathrm{L}$ [13]. We studied the association of basal $\mathrm{T}$ levels with ovarian response and IVF outcome in the two groups. Informed consent was obtained from all subjects. This study received institutional review board approval from the ethical committee of Shandong University.

\section{Study protocol}

Long luteal down-regulation protocol was used in all patients. Briefly, the gonadotropinreleasing hormone (GnRH) agonist (0.1 mg/ampoule, Tryptorelin, Ferring, Germany) was administered in the midluteal phase of the previous cycle until the day of HCG administration. After onset of menstrual bleeding, when satisfactory pituitary desensitization was achieved (serum E2 level was lower than $50 \mathrm{pg} / \mathrm{ml}$ ), gonadotropin stimulation was started with a daily use of recombinant FSH (75 U/ ampoule, Gonal F, Serono. Ltd, Switzerland). The dose of gonadotropins was adjusted according to follicular growth monitored by transvaginal ultrasonography and serum E2 concentrations. HCG (10,000 IU) (Lizhu. Ltd, Guangdong, China) was given when at least two follicles reached $18 \mathrm{~mm}$ in diameter and 36 hours later oocytes were retrieved by transvaginal ultrasound-guided follicular aspiration. Up to three embryos per patient were transferred (2 embryos were transferred for women aged $<35$ years old and in their first treatment cycle, 3 embryos were transferred for women aged $\geq 35$ years old or $\geq 2$ treatment cycles) 2 or 3 days after oocytes retrieval and the luteal phase was supported with progesterone $(20 \mathrm{mg} / \mathrm{ampoule}$, Xianju Ltd, Zhejiang, China). A positive pregnancy was defined by $>5 \mathrm{IU} / \mathrm{L}$ of plasma $\beta$-hCG on 14 days after embryo transfer. The fertilization rate was defined as the number of oocytes with two pronuclei after insemination divided by the number of oocytes inseminated. The spontaneous miscarriage was defined as both biochemical and clinical miscarriages. The good quality embryos were defined as embryos developed from normal fertilized eggs with no fragmentation or no more than $1 / 3$, no presence of multinucleation, 3 5 blastomeres at 48 hours after egg retrieval and at least 7 blastomeres by $72 \mathrm{~h}$ [16].

\section{Hormone assays}

On day 2 to 4 of the menstrual cycle, basal serum levels of $\mathrm{T}, \mathrm{FSH}, \mathrm{E}_{2}$ and $\mathrm{LH}$ were obtained from each subject. All the serum levels were determined by the electrochemiluminescent immunoassay in the analyzer cobas e 601 (Roche, Switzerland). The analytical sensitivity of basal T, FSH, LH, $\mathrm{E}_{2}$ and $\beta$-hCG levels was $0.42 \mathrm{ng} / \mathrm{ml},<0.10 \mathrm{mIU} / \mathrm{ml}, 0.10$ $\mathrm{mIU} / \mathrm{ml}, 5.0 \mathrm{pg} / \mathrm{ml}$ and $<0.1 \mathrm{mIU} / \mathrm{ml}$, respectively.

\section{Statistical analysis}

The pretreatment parameters included age, body mass index (BMI), pregnancy history, AFC, starting doses of gonadotropins and basal levels of FSH, $\mathrm{E}_{2}, \mathrm{LH}$, and T.

To assess the predictive value of basal $\mathrm{T}$ levels to the ovarian response, we studied the associations of basal $\mathrm{T}$ levels with the number of oocytes retrieved, number of follicles $>14 \mathrm{~mm}$ on HCG day, basal FSH/LH ratio, days of stimulation and total dose of gonadotropins.

To evaluate IVF outcome, we analyzed the following variables: endometrial thickness on HCG day, fertilization rate, number of embryos cryopreserved, number of good quality embryos, pregnancy and spontaneous miscarriage outcome and live births. 
Student's t-test and analysis of covariance (ANCOVA) were performed to examine the differences in means between the pregnant group and the non-pregnant group. Pearson correlation tests and partial correlation analyses were used to assess the relationship between basal $\mathrm{T}$ levels and the continuous parameters. Multiple linear regression analyses were used to find the possible independent determinants of test variables among those parameters showing significant correlations and their contributions. The area under the receiver operating characteristic curve (ROC) was performed to examine the predictive value for pregnancy and spontaneous miscarriage outcome. Data were analyzed with SPSS statistical package (SPSS version 13.0, Chicago, IL). Continuous values were presented as mean \pm SD and all tests were two-tailed. $\mathrm{P}<0.05$ was considered statistically significant.

\section{Results}

Table 1 showed the comparison of characteristics and $\mathrm{COH}$ parameters between pregnant and non-pregnant (excluded patients who did not have embryo transferred) women in Group 1 and 2. In Group 1, basal T levels were significantly higher in the pregnant women than that in non-pregnant ones $(\mathrm{p}<0.05)$, while as not in Group 2. When adjusting for age yielded similar results. It seemed that pregnant women in Group 1 had more good quality embryos, embryos cryopreservered and more gonadotropins used than non-pregnant patients.
In Group 1, pearson rank correlation analysis showed positive associations between basal $\mathrm{T}$ levels with the number of follicles $>14 \mathrm{~mm}$ on HCG day, but negative associations with age, days of stimulation and total dose of gonadotropins used. When adjusting for age yielded similar results (Table 2). In the pearson rank correlation analysis, the characteristics associated with number of follicles $>14 \mathrm{~mm}$ on HCG day were age, BMI, AFC, basal T levels, basal FSH levels, basal LH levels and starting dose of gonadotropins, respectively (data not shown). For total dose of gonadotropins, the associated characteristics were age, BMI, AFC, basal T levels, basal FSH levels and starting dose of gonadotropins, respectively (data not shown). And the characteristics correlated with days of stimulation were basal $\mathrm{T}$ levels and AFC (data not shown). Accordingly, multiple linear regression analysis were performed to study the major independent factors for number of follicles $>14 \mathrm{~mm}$ on HCG day, total dose of gonadotropins and days of stimulation which were used as the dependent variable, whereas independent variables included the characteristics showing significant correlations mentioned above respectively (Table 3, 4, 5). Basal T level was an independent factor for number of follicles $>14 \mathrm{~mm}$ on HCG day, total dose of gonadotropins and days of stimulation. For number of follicles $>14$ $\mathrm{mm}$ on HCG day, the influencing independent factor with decreasing importance were basal FSH levels, AFC, basal LH levels, basal T levels and age. For total dose of gonadotropins, the largest influencing independent factor

Table 1 The comparison of characteristics and $\mathrm{COH}$ parameters between pregnant and non-pregnant women

\begin{tabular}{|c|c|c|c|c|c|c|}
\hline \multirow[b]{2}{*}{ Variables } & \multicolumn{3}{|c|}{ Group 1} & \multicolumn{3}{|c|}{ Group 2} \\
\hline & $\begin{array}{l}\text { Non-pregnant cycles } \\
\mathrm{n}=89 \text { ) }\end{array}$ & $\begin{array}{l}\text { Pregnant cycles } \\
(n=72)\end{array}$ & $P$ value & $\begin{array}{l}\text { Non-pregnant cycles } \\
(n=403)\end{array}$ & $\begin{array}{l}\text { Pregnant cycles } \\
(\mathrm{n}=518)\end{array}$ & $P$ value \\
\hline Age (years) & $32.2 \pm 4.0$ & $32.7 \pm 3.8$ & 0.352 & $31.9 \pm 4.0$ & $31.1 \pm 4.1$ & 0.003 \\
\hline BMI $\left(\mathrm{kg} / \mathrm{m}^{2}\right)$ & $22.4 \pm 2.9$ & $2.2 \pm 2.6$ & 0.696 & $9.4 \pm 1.5$ & $9.4 \pm 1.4$ & 0.312 \\
\hline Pregnancy history & $0.6 \pm 0.5$ & $0.6 \pm 0.5$ & 0.628 & $9.0 \pm 3.9$ & $9.0 \pm 3.8$ & 0.930 \\
\hline Basal FSH levels (IU/L) & $11.8 \pm 1.9$ & $11.6 \pm 1.7$ & 0.424 & $7.5 \pm 1.4$ & $7.5 \pm 1.4$ & 0.947 \\
\hline Basal LH levels (IU/L) & $5.4 \pm 1.9$ & $5.0 \pm 2.1$ & 0.260 & $4.3 \pm 2.2$ & $4.3 \pm 2.2$ & 0.974 \\
\hline Basal $E_{2}$ levels (pg/ml) & $43.3 \pm 20.8$ & $41.6 \pm 18.3$ & 0.581 & $43.3 \pm 30.5$ & $41.2 \pm 31.4$ & 0.300 \\
\hline Basal T levels (ng/dl) & $48.3 \pm 17.3$ & $40.8 \pm 18.1$ & 0.008 & $47.8 \pm 18.9$ & $47.7 \pm 19.9$ & 0.907 \\
\hline Antral follicle count & $9.8 \pm 4.3$ & $8.6 \pm 4.6$ & 0.099 & $11.6 \pm 5.5$ & $11.2 \pm 5.7$ & 0.217 \\
\hline Starting dose of gonadotropins (IU) & $223.3 \pm 54.6$ & $228.1 \pm 67.3$ & 0.617 & $203.6 \pm 36.7$ & $198.6 \pm 40.7$ & 0.053 \\
\hline Number of oocytes retrieved & $10.0 \pm 4.4$ & $9.0 \pm 4.7$ & 0.171 & $12.4 \pm 5.4$ & $12.4 \pm 5.3$ & 0.999 \\
\hline Number of follicles >14 mm & $7.8 \pm 3.5$ & $7.1 \pm 3.5$ & 0.176 & $9.0 \pm 3.9$ & $9.0 \pm 3.8$ & 0.761 \\
\hline Days of stimulation & $9.7 \pm 1.6$ & $10.5 \pm 1.9$ & 0.002 & $9.4 \pm 1.5$ & $9.4 \pm 1.4$ & 0.744 \\
\hline Total dose of gonadotropins (IU) & $2477.8 \pm 873.9$ & $2936.1 \pm 1249.9$ & 0.010 & $2174.2 \pm 826.8$ & $2042.3 \pm 728.7$ & 0.012 \\
\hline Endometrial thickness on HCG day $(\mathrm{cm})$ & $1.1 \pm 0.2$ & $1.1 \pm 0.2$ & 0.521 & $1.0 \pm 0.2$ & $1.1 \pm 0.2$ & 0.001 \\
\hline Fertilization rate & $0.8 \pm 0.2$ & $0.7 \pm 0.2$ & 0.202 & $0.7 \pm 0.2$ & $0.7 \pm 0.2$ & 0.615 \\
\hline Number of embryos cryopreserved & $3.3 \pm 2.9$ & $2.4 \pm 2.4$ & 0.034 & $3.9 \pm 3.4$ & $4.1 \pm 3.2$ & 0.256 \\
\hline Number of good quality embryos & $5.6 \pm 2.9$ & $4.5 \pm 2.5$ & 0.015 & $6.0 \pm 3.4$ & $6.3 \pm 3.2$ & 0.219 \\
\hline
\end{tabular}

Note: Data other than $\mathrm{P}$ values are mean \pm SD.

Dichotomy variable pregnancy history was represented by secondary infertility $=1$ and primary infertility $=0$. 
Table 2 Spearman correlation analysis of associations between basal T levels and the characteristics and COH parameters

\begin{tabular}{|c|c|c|c|c|c|c|c|c|}
\hline \multirow[b]{2}{*}{ Variables } & \multicolumn{4}{|c|}{ Group 1} & \multicolumn{4}{|c|}{ Group 2} \\
\hline & $r$ value & $P$ value & rvalue $^{a}$ & $P$ value $^{\mathrm{a}}$ & $r$ value & $P$ value & $r_{\text {value }}{ }^{b}$ & P value ${ }^{b}$ \\
\hline Age (years) & -0.163 & 0.026 & - & - & -0.151 & $<0.001$ & - & - \\
\hline BMI $\left(\mathrm{kg} / \mathrm{m}^{2}\right)$ & -0.054 & 0.308 & -0.009 & 0.907 & -0.063 & 0.038 & - & - \\
\hline Pregnancy history & -0.031 & 0.669 & 0.013 & 0.859 & -0.033 & 0.276 & 0.011 & 0.714 \\
\hline Basal FSH level (IU/L) & -0.051 & 0.068 & -0.032 & 0.664 & 0.028 & 0.361 & 0.033 & 0.281 \\
\hline Basal LH level (IU/L) & 0.026 & 0.722 & 0.007 & 0.927 & 0.080 & 0.009 & - & - \\
\hline Basal $E_{2}$ level (pg/ml) & 0.141 & 0.054 & 0.134 & 0.069 & -0.044 & 0.150 & -0.036 & 0.239 \\
\hline Antral follicle count & 0.026 & 0.724 & 0.002 & 0.979 & 0.044 & 0.151 & 0.015 & 0.631 \\
\hline Starting dose of gonadotropins (IU) & -0.088 & 0.434 & -0.009 & 0.902 & -0.124 & $<0.001$ & - & - \\
\hline Basal FSH/LH ratio & -0.014 & 0.849 & 0.013 & 0.856 & -0.056 & 0.065 & 0.006 & 0.839 \\
\hline Numbers of oocytes retrieved & 0.115 & 0.117 & 0.063 & 0.394 & 0.064 & 0.037 & 0.009 & 0.766 \\
\hline Number of follicles >14 mm & 0.191 & 0.009 & 0.147 & 0.047 & 0.013 & 0.679 & -0.036 & 0.246 \\
\hline Days of stimulation & -0.174 & 0.017 & -0.177 & 0.016 & -0.076 & 0.013 & -0.066 & 0.031 \\
\hline Total dose of gonadotropins (IU) & -0.203 & 0.005 & -0.155 & 0.035 & -0.139 & $<0.001$ & -0.081 & 0.008 \\
\hline Endometrial thickness on HCG day $(\mathrm{cm})$ & 0.120 & 0.102 & 0.093 & 0.211 & -0.027 & 0.380 & -0.041 & 0.177 \\
\hline Fertilization rate & -0.010 & 0.893 & -0.007 & 0.930 & -0.007 & 0.828 & 0.003 & 0.922 \\
\hline Number of embryos cryopreserved & 0.069 & 0.347 & 0.020 & 0.791 & 0.058 & 0.058 & 0.009 & 0.766 \\
\hline Number of good quality embryos & 0.060 & 0.412 & 0.022 & 0.771 & 0.040 & 0.190 & 0.002 & 0.956 \\
\hline Live births & -0.009 & 0.906 & -0.022 & 0.765 & -0.024 & 0.427 & -0.023 & 0.452 \\
\hline
\end{tabular}

Note: ${ }^{a}$ represent the $\mathrm{r}$ value and $\mathrm{P}$ value after adjusting for age that associated with basal testosterone levels.

${ }^{\mathrm{b}}$ represent the $\mathrm{r}$ value and $\mathrm{P}$ value after adjusting for age, basal LH level, BMI and starting dose of gonadotropins that associated with basal testosterone levels. Dichotomy variable pregnancy history was represented by secondary infertility $=1$ and primary infertility $=0$.

was starting dose of gonadotropins, and with decreasing importance, basal FSH levels and basal T levels in order. For days of stimulation, the only influencing independent factor was basal $\mathrm{T}$ levels.

Table 6 shows the ROC curve analysis of the diagnostic accuracy of discriminination between pregnancy per transfer versus non-pregnancy per transfer, spontaneous miscarriage and non-spontaneous miscarriage. In the ROC model, basal $\mathrm{T}$ levels are predictive of pregnancy outcome in Group 1. A basal T level of $47.85 \mathrm{ng} / \mathrm{dl}$ was shown to predict pregnancy outcome with a sensitivity of $52.8 \%$ and specificity of $65.3 \%$.

\section{Discussion}

Androgen actions via the AR play an important role in female fertility $[17,18]$. It is believed that AR signaling in granulosa cells (GCs) is necessary for normal follicular growth and progression beyond preantral stage [19]. Inhibition of ARs slows mouse follicle growth [20], decreases the diameter of mouse follicles [21,22] and induces GC degeneration and follicular apoptosis. Low numbers of antral follicles, ovulated oocytes, and a high rate of follicular atresia were found in the global and GC-specific ARKO mice $[23,24]$. In this study, basal $\mathrm{T}$ level in women with diminished ovarian reserve

Table 3 Multiple linear regression analysis of possible determinants for number of follicles $>14 \mathrm{~mm}$ in $\mathrm{Group} 1$

\begin{tabular}{|c|c|c|c|c|c|}
\hline \multirow[b]{3}{*}{ Independent variables } & \multicolumn{4}{|c|}{ Coefficients } & \multirow[b]{3}{*}{$P$ value } \\
\hline & \multicolumn{2}{|c|}{ Unstandardized coefficients } & \multicolumn{2}{|c|}{ Standardized coefficients } & \\
\hline & $\beta$ & Std. Error & $\beta$ & $\mathbf{t}$ & \\
\hline (constant) & 15.654 & 3.387 & & 4.622 & $<0.001$ \\
\hline Age (years) & -0.151 & 0.074 & -0.157 & -2.027 & 0.044 \\
\hline $\mathrm{BMI}\left(\mathrm{kg} / \mathrm{m}^{2}\right)$ & -0.092 & 0.100 & -0.066 & -0.915 & 0.361 \\
\hline Basal T levels (ng/dl) & 0.028 & 0.014 & 0.136 & 2.032 & 0.044 \\
\hline Basal FSH level (IU/L) & -0.414 & 0.126 & -0.227 & -3.288 & 0.001 \\
\hline Basal LH level (IU/L) & 0.330 & 0.134 & 0.175 & 2.459 & 0.015 \\
\hline Antral follicle count & 0.150 & 0.054 & 0.186 & 2.777 & 0.006 \\
\hline Starting dose of gonadotropins (IU) & -0.003 & 0.005 & -0.047 & -0.624 & 0.534 \\
\hline
\end{tabular}

Note: The dependent variable is number of follicles $>14 \mathrm{~mm}$. The model $\left(r=0.475, r^{2}=0.225\right.$, adjusted $\left.r^{2}=0.195, P<0.001\right)$.

The values of the standardized coefficients reflect the independent contributions of each predictor to dependent variables. 
Table 4 Multiple linear regression analysis of possible determinants for total dose of gonadotropins in Group 1

\begin{tabular}{|c|c|c|c|c|c|}
\hline \multirow[b]{3}{*}{ Independent variables } & \multicolumn{4}{|c|}{ Coefficients } & \multirow[b]{3}{*}{$P$ value } \\
\hline & \multicolumn{2}{|c|}{ Unstandardized coefficients } & \multicolumn{2}{|c|}{ Standardized coefficients } & \\
\hline & $\beta$ & Std. Error & $\beta$ & $\mathbf{t}$ & \\
\hline (constant) & -464.984 & 819.634 & & -0.567 & 0.571 \\
\hline Age (years) & -8.988 & 18.659 & -0.032 & -0.482 & 0.631 \\
\hline BMI $\left(\mathrm{kg} / \mathrm{m}^{2}\right)$ & 40.781 & 25.082 & 0.098 & 1.626 & 0.106 \\
\hline Basal T levels (ng/dl) & -8.833 & 3.516 & -0.145 & 2.512 & 0.013 \\
\hline Basal FSH level (IU/L) & 89.904 & 31.525 & 0.166 & 2.852 & 0.005 \\
\hline Antral follicle count & -26.244 & 13.797 & -0.109 & -1.902 & 0.059 \\
\hline Starting dose of gonadotropins (IU) & 9.633 & 1.168 & 0.531 & 8.244 & $<0.001$ \\
\hline
\end{tabular}

Note: The dependent variable is total dose of gonadotropins. The model $\left(r=0.647, r^{2}=0.419\right.$, adjusted $\left.r^{2}=0.399, P<0.001\right)$.

The values of the standardized coefficients reflect the independent contributions of each predictor to dependent variables.

positively correlates with the number of large follicles $(>14 \mathrm{~mm})$ significantly. This is in agreement with previous studies mentioned above.

With IVF being an invasive, stressful, time-consuming and expensive treatment, it is important to help couples select the best individualized strategy for $\mathrm{COH}$. Predicting the ovarian response is useful in ameliorating subsequent disappointment and distress of potential poor responders as well as in optimizing the gonadotropins stimulation protocol to obtain a good response. Although no significant association between basal $\mathrm{T}$ levels and oocytes retrieved was found, basal $\mathrm{T}$ level is an independent factor for both days of stimulation and total dose of gonadotropins in both groups. In other words, in order to reach similar ovarian response, patients with lower basal $\mathrm{T}$ levels needed more days and more doses of gonadotropins otherwise they might show poor ovarian response.

Basal FSH/LH ratio is suggested to predict ovarian response and IVF outcome, although the definite threshold value is still controversial $[25,26]$. We assessed the correlation of basal FSH/LH ratio and basal T level for the first time in the present study and found no significant association in the two groups. Further prospective studies are needed to elucidate the subject.

The application of basal serum $\mathrm{T}$ levels for predicting pregnancy outcome is debated. John L et al. suggested basal testosterone levels $\leq 20 \mathrm{ng} / \mathrm{dL}$ was associated with poor IVF success rates [27]. But later, the same group and Barbieri RL denied the predictive value in other studies $[15,28]$. In this study, we showed for the first time that basal $\mathrm{T}$ level could predict pregnancy outcome in women with diminished ovarian reserve. We compared the relative performance of basal T level with basal FSH, basal E2 and AFC using ROC curve further as a predictor of pregnancy outcome in Group 1. Only basal T levels was a significant indicator for pregnancy outcome. There is no report focusing on the relationship between basal $\mathrm{T}$ level and spontaneous miscarriage outcome at present. Our results showed that, on pregnancy outcome, basal $\mathrm{T}$ levels had minimal effects, and for the first time, no association with spontaneous miscarriage. As is known to all, a successful IVF treatment is dependent on ovarian response, as well as oocyte quality, male factors and endometrial factors. Although basal T level is associated with potential ovarian response in women with normal ovarian reserve according to the present study, it could not predict the pregnancy outcome as expected.

A weakness of this study is only basal serum testosterone level, which is ovarian androgen, was evaluated. DHEA and other adrenal androgens are also very important as shown in previous studies [6,29]. Further prospective investigations on adrenal androgens are warranted in prospective studies.

One strength of our study is the largest sample size (total 1260 patients) so far. Secondly, different from previous studies $[15,27,28]$, the population we investigated

Table 5 Multiple linear regression analysis of possible determinants for days of stimulation

\begin{tabular}{|c|c|c|c|c|c|}
\hline \multirow[b]{3}{*}{ Independent variables } & \multicolumn{4}{|c|}{ Coefficients } & \multirow[b]{3}{*}{$P$ value } \\
\hline & \multicolumn{2}{|c|}{ Unstandardized coefficients } & \multicolumn{2}{|c|}{ Standardized coefficients } & \\
\hline & $\beta$ & Std. Error & $\beta$ & $\mathbf{t}$ & \\
\hline (constant) & 11.388 & 0.427 & & 26.661 & $<0.001$ \\
\hline Basal T levels (ng/dl) & -0.017 & 0.007 & -0.170 & -2.367 & 0.019 \\
\hline Antral follicle count & -0.054 & 0.028 & -0.141 & -1.964 & 0.051 \\
\hline
\end{tabular}

Note: The dependent variable is days of stimulation. The model $\left(r=0.224, r^{2}=0.050\right.$, adjusted $\left.r^{2}=0.040, P=0.009\right)$.

The values of the standardized coefficients reflect the independent contributions of each predictor to dependent variables. 
Table 6 Receiver operating characteristic curve analysis of study variables for the prediction of IVF outcome

\begin{tabular}{|c|c|c|c|c|c|c|c|}
\hline & Variables & $A \cup C_{R O C}$ & Optimum cutoff & Sensitivity \% & Specificity \% & $95 \% \mathrm{Cl}$ & $P$ value \\
\hline \multirow[t]{2}{*}{ Group 1} & Pregnancy per transfer & 0.609 & 47.85 & 52.8 & 65.3 & $0.521-0.696$ & 0.018 \\
\hline & Spontaneous miscarriage & 0.396 & 18.24 & 100 & 4.1 & $0.245-0.548$ & 0.196 \\
\hline \multirow[t]{2}{*}{ Group 2} & Pregnancy per transfer & 0.508 & 47.26 & 52.3 & 52.9 & $0.470-0.546$ & 0.673 \\
\hline & Spontaneous miscarriage & 0.505 & 54.76 & 40.0 & 67.4 & $0.441-0.569$ & 0.871 \\
\hline
\end{tabular}

Note: $\mathrm{AUC}_{\mathrm{ROC}}=$ area under the receiver operating characteristic curve; $\mathrm{Cl}=$ confidence interval.

was excluded PCOS and endometriosis. Different kinds of protocols used other than long protocol was ruled out. And we adjusted for confounding variables including age, BMI, treatment cycles, infertility history and starting dose of gonadotropins given their possible associations with basal serum $\mathrm{T}$ levels. It is reported that age, BMI and causes of infertility may involve in ovarian response and/or pregnancy outcome [30-32]. Therefore, patients in our study were matched for these variables, allowing the analysis of basal $\mathrm{T}$ levels as an independent marker for test variables. Besides, although this is a retrospective study, ascertainment and recall bias were minimized as all the data were collected and recorded in the computerized database.

\section{Conclusions}

Basal $\mathrm{T}$ level is a good predictor for pregnancy outcome and number of large follicles on HCG day in women with diminished ovarian reserve. Basal $\mathrm{T}$ level is equally helpful in tailoring the dosage of gonadotropins to individual and identifying potential poor ovarian responders, subsequently, making individualized $\mathrm{COH}$ strategy before entering IVF cycles. It also gives evidence to androgen supplementation in infertile women. Those patients with lower basal $\mathrm{T}$ levels would benefit from $\mathrm{T}$ supplementation during $\mathrm{COH}$, such as improving response, decreasing the amount of gonadotropins used and the cost accordingly.

\footnotetext{
Abbreviations

IVF: in vitro fertilization; PCOS: polycystic ovary syndrome; AFC: antral follicle count; $\mathrm{AMH}$ : anti-Müllerian hormone; FSH: follicle stimulating hormone; $\mathrm{E}_{2}$ : estradiol; IGF-1: insulin like growth factor 1; $\mathrm{COH}$ : controlled ovarian hyperstimulation; $\mathrm{GnRH}$ : gonadotropinreleasing hormone; T: testosterone; ANCOVA: analysis of covariance; DHEA: Dehydroepiandrosterone; GCs: granulosa cells.
}

\section{Acknowledgements}

We gratefully thank all the participants who were enrolled in this study. This study was supported by grants from the National Natural Science Foundation of China (30973170, 81070461, 81000236, 81000238), and China Postdoctoral Science Foundation funded project (10000058311050, 10000058311715).

\section{Author details}

${ }^{1}$ Center for Reproductive Medicine, Shandong Provincial Hospital, Shandong University, Jinan, 250021, PR China. ${ }^{2}$ Key Laboratory of Reproductive Medicine, Shandong Province, PR China. ${ }^{3}$ Case Western Reserve University, Cleveland, $\mathrm{OH}$ 44146, USA.

\section{Authors' contributions}

ZC designed the study and supervised patients' diagnosis, samples recruitment and experiments performance. $Z Z$ conducted data analysis and drafted the manuscript. MS and LG recruited samples. YQ revised the manuscript, performed statistical analysis and endocrine biochemical examination. LC revised the manuscript. All authors read and approved the final manuscript.

\section{Competing interests}

The authors declare that they have no competing interests.

Received: 29 October 2010 Accepted: 20 January 2011

Published: 20 January 2011

\section{References}

1. Kwee J, Elting MW, Schats R, Bezemer PD, Lambalk CB, Schoemaker J: Comparison of endocrine tests with respect to their predictive value on the outcome of ovarian hyperstimulation in IVF treatment: results of a prospective randomized study. Hum Reprod 2003, 18:1422-1427.

2. Steckler T, Wang J, Bartol FF, Roy SK, Padmanabhan V: Fetal programming: prenatal testosterone treatment causes intrauterine growth retardation, reduces ovarian reserve and increases ovarian follicular recruitment. Endocrinology 2005, 146:3185-3193.

3. Vendola K, Zhou J, Wang J, Famuyiwa OA, Bievre M, Bondy CA: Androgens promote oocyte insulin-like growth factor I expression and initiation of follicle development in the primate ovary. Biol Reprod 1999, 61:353-357.

4. Vendola KA, Zhou J, Adesanya OO, Weil SJ, Bondy CA: Androgens stimulate early stages of follicular growth in the primate ovary. J Clin Invest 1998, 101:2622-2629.

5. Vendola K, Zhou J, Wang J, Bondy CA: Androgens promote insulin-like growth factor-I and insulin-like growth factor-I receptor gene expression in the primate ovary. Hum Reprod 1999, 14:2328-2332.

6. Barad D, Brill H, Gleicher N: Update on the use of dehydroepiandrosterone supplementation among women with diminished ovarian function. J Assist Reprod Genet 2007, 24:629-634.

7. Fábregues F, Peñarrubia J, Creus M, Manau D, Casals G, Carmona F, Balasch J: Transdermal testosterone may improve ovarian response to gonadotrophins in low-responder IVF patients: a randomized, clinical trial. Hum Reprod 2009, 24:349-359.

8. Mamas L, Mamas E: Premature ovarian failure and dehydroepiandrosterone. Fertil Steril 2009, 91:644-646.

9. Balasch J, Fábregues F, Peñarrubia J, Carmona F, Casamitjana R, Creus M, Manau D, Casals G, Vanrell JA: Pretreatment with transdermal testosterone may improve ovarian response to gonadotrophins in poorresponder IVF patients with normal basal concentrations of FSH. Hum Reprod 2006, 21:1884-93.

10. Goswami SK, Das T, Chattopadhyay R, Sawhney V, Kumar J, Chaudhury K, Chakravarty BN, Kabir SN: A randomized single-blind controlled trial of letrozole as a low-cost IVF protocol in women with poor ovarian response: a preliminary report. Hum Reprod 2004, 19:2031-2035.

11. Mitwally MF, Casper RF: Aromatase inhibition improves ovarian response to follicle-stimulating hormone in poor responders. Fertil Steril 2002, 77:776-780.

12. Massin N, Cedrin-Durnerin I, Coussieu C, Galey-Fontaine J, Wolf JP, Hugues JN: Effects of transdermal testosterone application on the ovarian response to $\mathrm{FSH}$ in poor responders undergoing assisted reproduction technique-a prospective, randomized, double-blind study. Hum Reprod 2006, 21:1204-11.

13. Li L, Ferin M, Sauer MV, Lobo RA: Dehydroepiandrosterone in follicular fluid is produced locally, and levels correlate negatively with in vitro fertilization outcomes. Fertil Steril 2010. 
14. Wachs DS, Coffler MS, Malcom PJ, Shimasaki S, Chang RJ: Increased androgen response to follicle-stimulating hormone administration in women with polycystic ovary syndrome. I Clin Endocrinol Metab 2008, 93:1827-1833.

15. Barbieri RL, Sluss PM, Powers RD, McShane PM, Vitonis A, Ginsburg E, Cramer DC: Association of body mass index, age, and cigarette smoking with serum testosterone levels in cycling women undergoing in vitro fertilization. Fertil Steril 2005, 83:302-308.

16. Puissant F, Van Rysselberge M, Barlow P, Deweze J, Leroy F: Embryo scoring as a prognostic tool in IVF treatment. Hum Reprod 1987, 2:705-708.

17. Yang MY, Fortune JE: Testosterone stimulates the primary to secondary follicle transition in bovine follicles in vitro. Biol Reprod 2006, 75:924-932

18. Walters KA, Allan CM, Handelsman DJ: Androgen actions and the ovary. Biol Reprod 2008, 78:380-389.

19. Sen A, Hammes SR: Granulosa cell-specific androgen receptors are critical regulators of ovarian development and function. Mol Endocrinol 2010, 24:1393-403.

20. Murray AA, Gosden RG, Allison V, Spears N: Effect of androgens on the development of mouse follicles growing in vitro. J Reprod Fertil 1998, 113:27-33.

21. Wang $\mathrm{H}$, Andoh $\mathrm{K}$, Hagiwara $\mathrm{H}$, Xiaowei L, Kikuchi N, Abe $\mathrm{Y}, 1402$ Sen and Hammes: AR Signaling in Female Reproduction. Mol Endocrinol 2010, 24(7):1393-1403.

22. Yamada K, Fatima R, Mizunuma $\mathrm{H}$ : Effect of adrenal and ovarian androgens on type 4 follicles unresponsive to FSH in immature mice. Endocrinology 2001, 142:4930-4936.

23. Hu YC, Wang PH, Yeh S, Wang RS, Xie C, Xu Q, Zhou X, Chao HT, Tsai MY, Chang C: Subfertility and defective folliculogenesis in female mice lacking androgen receptor. Proc Natl Acad Sci USA 2004, 101:11209-112147.

24. Shiina $H$, Matsumoto $T$, Sato $T$, Igarashi K, Miyamoto J, Takemasa S, Sakari M, Takada I, Nakamura T, Metzger D, Chambon P, Kanno J, Yoshikawa $\mathrm{H}$, Kato S: Premature ovarian failure in androgen receptordeficient mice. Proc Natl Acad Sci USA 2006, 103:224-229.

25. Orvieto R, Meltzer S, Rabinson J, Gemer O, Anteby EY, Nahum R: Does day 3 luteinizing-hormone level predict IVF success in patients undergoing controlled ovarian stimulation with GnRH analogues? Fertil Steril 2008, 90:1297-1300.

26. Mukherjee T, Copperman AB, Lapinski R, Sandler B, Bustillo M, Grunfeld L: An elevated day three follicle-stimulating hormone: luteinizing hormone ratio (FSH:LH) in the presence of a normal day $3 \mathrm{FSH}$ predicts a poor response to controlled ovarian hyperstimulation. Fertil Steril 1996, 65:588-593.

27. Frattarelli $\mathrm{LL}$, Peterson EH: Effect of androgen levels on in vitro fertilization cycles. Fertil Steril 2004, 81:1713-1714.

28. Frattarelli $\mathrm{JL}$, Gerber MD: Basal and cycle androgen levels correlate with in vitro fertilization stimulation parameters but do not predict pregnancy outcome. Fertil Steril 2006, 86:51-57.

29. Barad D, Brill H, Gleicher N: Update on the use of dehydroepiandrosterone supplementation among women with diminished ovarian function. J Assist Reprod Genet 2007, 24:629-34.

30. Crosignani PG, Ragni G, Parazzini F, Wyssling H, Lombroso G, Perotti L: Anthropometric indicators and response to gonadotrophin for ovulation induction. Hum Reprod 1994, 9:420-423.

31. Loh S, Wang JX, Matthews CD: The influence of body mass index, basal FSH and age on the response to gonadotrophin stimulation in nonpolycystic ovarian syndrome patients. Hum Reprod 2002, 17:1207-1211.

32. Roseboom TJ, Vermeiden JP, Schoute E, Lens JW, Schats R: The probability of pregnancy after embryo transfer is affected by the age of the patient, cause of infertility, number of embryos transferred and the average morphology score, as revealed by multiple logistic regression analysis. Hum Reprod 1995, 10:3035-3041.

doi:10.1186/1477-7827-9-9

Cite this article as: Qin et al: Association of basal serum testosterone levels with ovarian response and in vitro fertilization outcome. Reproductive Biology and Endocrinology 2011 9:9.

\section{Submit your next manuscript to BioMed Central and take full advantage of:}

- Convenient online submission

- Thorough peer review

- No space constraints or color figure charges

- Immediate publication on acceptance

- Inclusion in PubMed, CAS, Scopus and Google Scholar

- Research which is freely available for redistribution 